\title{
Age estimation of the skeletal remains of a child
}

SADJ July 2019, Vol. 74 No. 6 p323 - p324

\section{VM Phillips}

\section{CASE REPORT}

I was requested by the Forensic Science Laboratory in Plattekloof, Cape Town, to examine the skull of juvenile skeletal remains which had been recovered in Graaf Reinet, Eastern Cape. The skull was delivered to me at the Oral Health Centre of the University of the Western Cape and receipt was signed to maintain the chain of evidence.

The skull and lower jaw of the child were skeletonized with no residual soft tissues. The mandible was fractured in the mid-line. There was a depressed fracture of the posterior skull (Figure 1). The mandibular segments were cemented with cyanoacrylate cement (Super-glue) to facilitate dental radiography (Figure 2).
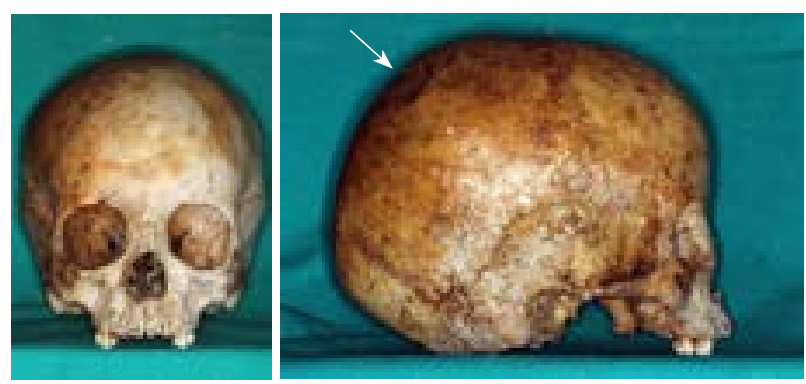

Figure 1. Frontal and lateral views of the skull of the child showing the mixed ethnic, predominantly Negroid, characteristics. The depressed fracture of the skull indicated (arrow).

Non-metric analysis of the skull of the child revealed mixed ethnic origin; with predominantly Negroid features (Fig. 1).
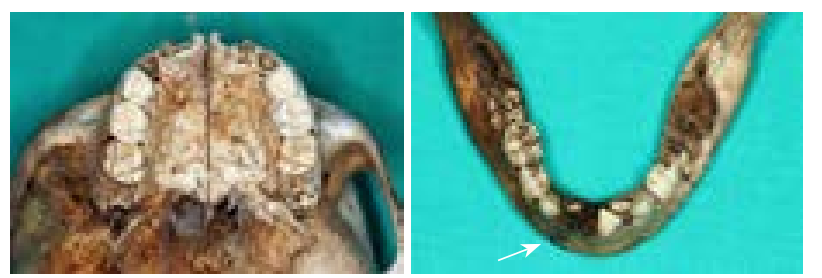

Figure 2. The maxilla and mandible, showing the loss of the deciduous front teeth and the underlying erupting permanent teeth, the post mortem loss of the left mandibular deciduous second molar (75) and the first permanent molar (36). The mandibular fracture is indicated (arrow).

\section{Author affiliations:}

Vincent M Phillips: BDS; MChD; Dip Max-Facial Radiology; FC Path SA (Oral Path); PhD; DSC, Emeritus Professor, Department of Oral and Maxillo-Facial Pathology and Forensic Science, Faculty of Health Sciences, University of the Western Cape, Cape Town, South Africa. ORCID Number: 0000-0003-1432-6274

Corresponding author: Vincent M Phillips

Department of Oral and Maxillo-Facial Pathology and Forensic Science, Faculty of Health Sciences, University of the Western

Cape, Cape Town, South Africa

Email: vmphillips@uwc.ac.za
The maxilla showed the loss of the deciduous incisors and canines with underlying and erupting permanent teeth. Both the mandible and maxilla had partially erupted first permanent molars present, apart from the 36 . The lower lateral incisors were starting to erupt lingually in the dental arch. There was a fracture of the anterior mandible in the region of right first incisor tooth and this tooth was missing (Fig. 2).

Periapical dental radiographs were taken of all the teeth in the upper and lower jaws (Fig. 3). These radiographic images were used in the determination of the dental developmental ages of the permanent mandibular teeth and thereby the estimated age of the child, using the Age Related Tables for South African children and juveniles (Table 1) (Tygerberg sample, Phillips 2009). ${ }^{1}$

The table shows the mean age at which the particular stage of calcification is visible, with the standard deviation in brackets. The Ac stage is omitted for age estimation. Only teeth that have not fully developed are used to estimate the age of the individual.

\section{RESULTS}

The calculation of the dental age is shown in the Table 2.

The estimated dental age of the child was calculated from the averages of the developmental ages of the teeth in the mandible.

\section{Age calculation}

The sum of the average developmental ages for seven permanent teeth in the mandible was calculated and the mean determined:

$\begin{array}{lcl}\text { Central incisor } & \text { I1 } & =5.37 \text { years } \\ \text { Lateral incisor } & \text { I2 } & =5.27 \text { years } \\ \text { Canine } & \text { C } & =5.30 \text { years } \\ \text { Premolar 1 } & \text { Pm1 } & =5.16 \text { years } \\ \text { Premolar 2 } & \text { Pm2 } & =5.30 \text { years } \\ \text { Molar 1 } & \text { M1 } & =5.45 \text { years } \\ \text { Molar 2 } & \text { M2 } & =5.42 \text { years } \\ \text { Average estimated age } & & =5.32 \text { years }\end{array}$

\section{CONCLUSION}

The skull and mandible of the child were assessed as being of mixed ethnic origin (mainly Negroid).

The dental age estimation of the child was 5.32 years (5 years 4 months) [SD $=6$ months]. 


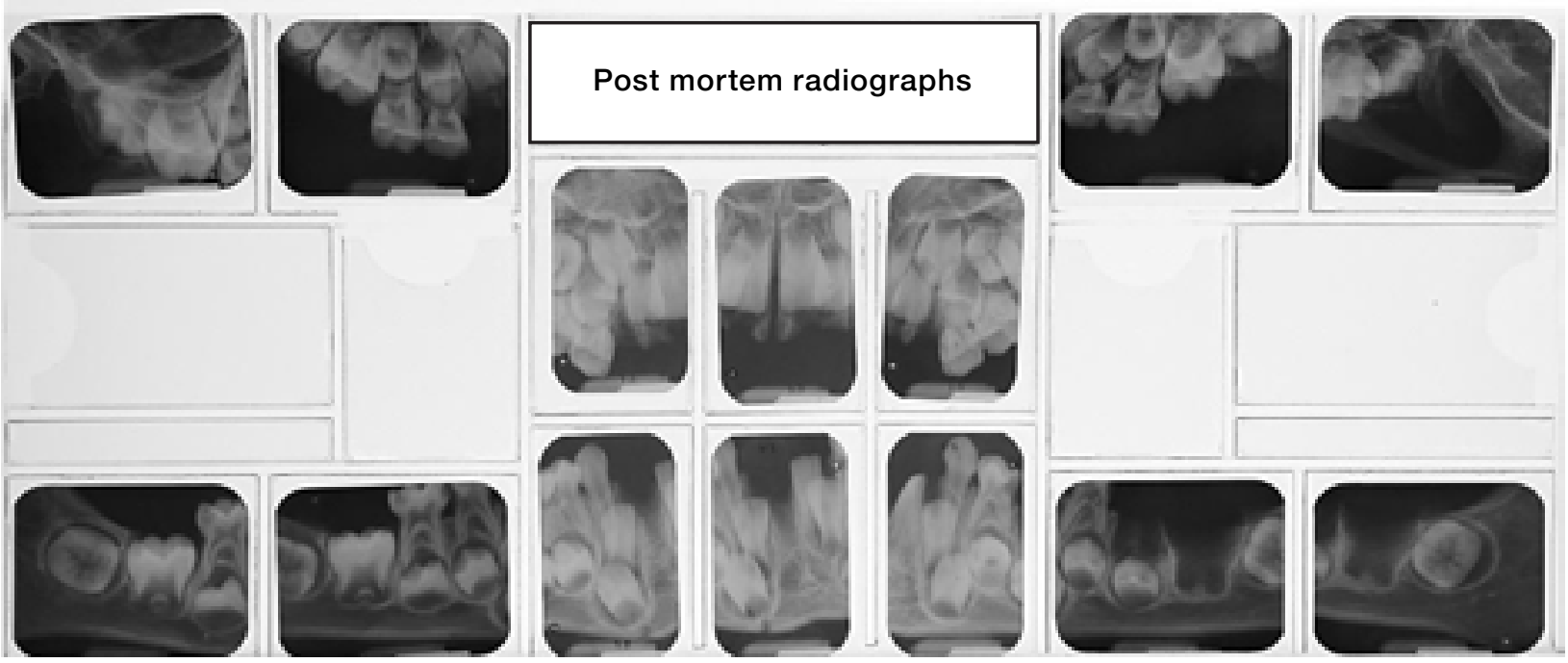

Figure 3. Full mouth periapical dental radiographs of teeth showing The lower left permanent first molar is absent, due to post mortem the various stages of calcification of the developing permanent teeth. desiccation of the tissues.

\begin{tabular}{|c|c|c|c|c|c|c|c|c|c|c|c|c|c|c|c|c|}
\hline \multirow[b]{2}{*}{$\mathrm{Fi}$} & \multicolumn{2}{|c|}{ I1 } & \multicolumn{2}{|c|}{12} & \multicolumn{2}{|c|}{ C } & \multicolumn{2}{|c|}{ Pm1 } & \multicolumn{2}{|c|}{ Pm2 } & \multicolumn{2}{|c|}{ M1 } & \multicolumn{2}{|c|}{ M2 } & \multicolumn{2}{|c|}{ M3 } \\
\hline & & & & & & & & & & & & & & & & \\
\hline$F$ & & & & & & & & & 4.44 & $(0.85)$ & & & & & 8.85 & $(1.39)$ \\
\hline $\mathrm{Ci}$ & & & & & & & & & 4.74 & $(1.06)$ & & & 4.13 & $(0.64)$ & 9.29 & (1.16) \\
\hline Cco & & & & & & & & & 4.97 & $(0.74)$ & & & 4.74 & (1.47) & 10.40 & (1.34) \\
\hline Coc & & & & & & & 3.26 & & 4.78 & $(1.00)$ & & & 4.75 & $(0.53)$ & 10.98 & $(1.05)$ \\
\hline $\mathrm{Cr} 1 / 2$ & & & & & 4.14 & & 4.65 & $(0.65)$ & 5.30 & $(0.80)$ & & & 5.42 & $(0.82)$ & 12.08 & (1.12) \\
\hline $\mathrm{Cr} 3 / 4$ & & & 3.96 & $(0.27)$ & 4.70 & $(0.75)$ & 5.16 & $(0.72)$ & 6.21 & $(0.74)$ & 3.26 & & 6.28 & $(0.81)$ & 12.62 & (1.38) \\
\hline Crc & 4.06 & $(0.36)$ & 4.74 & $(0.78)$ & 5.30 & $(0.94)$ & 6.29 & $(0.95)$ & 7.39 & $(0.88)$ & 4.04 & $(0.24)$ & 7.56 & $(1.00)$ & 13.38 & (1.24) \\
\hline $\mathrm{Ri}$ & 4.53 & (0.61) & 5.27 & $(0.70)$ & 6.11 & (0.81) & 7.13 & $(0.87)$ & 8.23 & $(0.90)$ & & & 8.29 & $(0.76)$ & 14.18 & (1.44) \\
\hline Cli & & & & & & & & & & & 4.70 & (0.92) & 8.77 & (0.95) & 15.09 & (1.09) \\
\hline $\mathrm{R} 1 / 4$ & 5.37 & $(0.65)$ & 6.02 & $(0.60)$ & 7.42 & $(0.94)$ & 8.26 & $(0.90)$ & 9.14 & $(1.17)$ & 5.45 & $(0.86)$ & 10.04 & $(1.00)$ & 15.24 & $(0.96)$ \\
\hline $\mathrm{R} 1 / 2$ & 6.07 & $(0.54)$ & 6.78 & $(0.88)$ & 8.52 & (1.03) & 9.63 & (1.06) & 10.45 & (1.04) & 6.25 & $(0.55)$ & 11.05 & (1.01) & & \\
\hline $\mathrm{R} 3 / 4$ & 6.89 & $(0.93)$ & 7.35 & $(0.66)$ & 10.00 & (1.17) & 10.50 & (1.01) & 11.09 & (1.15) & 7.25 & $(0.77)$ & 11.73 & $(0.77)$ & & \\
\hline Rc & 7.25 & $(0.58)$ & 8.08 & $(0.70)$ & 11.23 & $(1.10)$ & 11.41 & $(0.83)$ & 12.06 & (1.02) & 8.05 & $(0.76)$ & 12.60 & (0.91) & & \\
\hline $\mathrm{A} 1 / 2$ & 8.02 & $(0.68)$ & 8.76 & $(0.78)$ & 12.14 & $(0.96)$ & 12.14 & $(0.77)$ & 12.72 & (1.16) & 9.10 & $(0.85)$ & 14.04 & (1.06) & & \\
\hline Ac & & & & & & & & & & & & & & & & \\
\hline
\end{tabular}

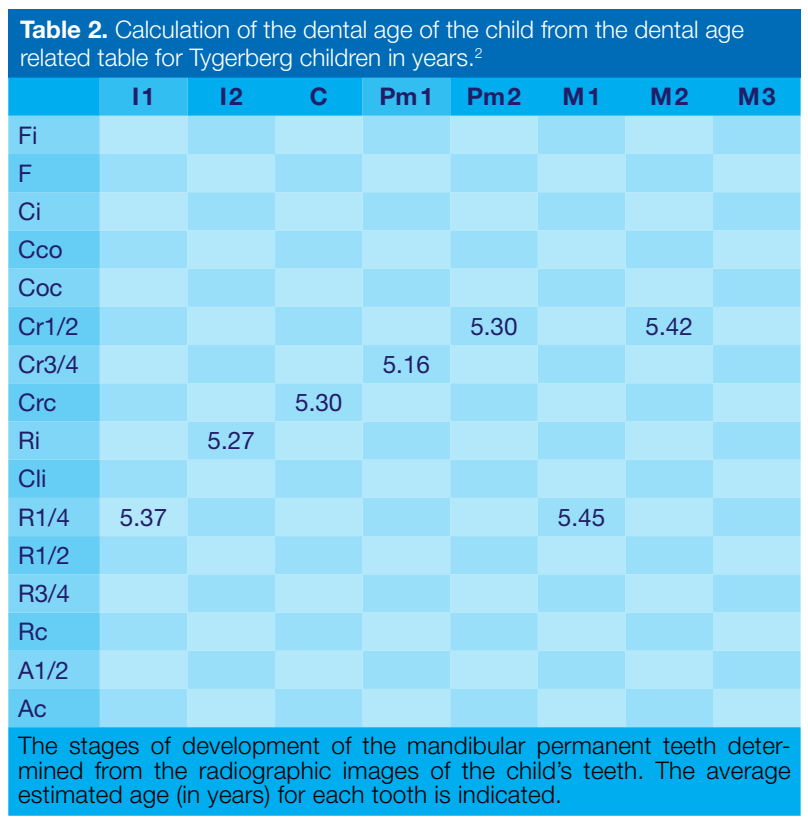

\section{References}

1. Phillips VM. Dental age related tables for children of various ethnic groups in South Africa. The Journal of Forensic Odonto-Stomatology 2009; 27(2): 29-44.

2. Phillips VM, van Wyk Kotze TJ. Testing standard methods of age estimation by Moorrees, Fanning \& Hunt and Demirjian, Goldstein \& Tanner on three South African children samples. The Journal of Forensic Odonto-Stomatology 2009; 27(2); 20-28. 